\title{
HUBUNGAN PERAN KADER TERHADAP KUNJUNGAN IBU BALITA DI POSYANDU KENANGA KAMPUNG JAWA KELURAHAN SEKANAK RAYA BELAKANG PADANG KOTA BATAM
}

Septi Maisyaroh Ulina Panggabean,

\begin{abstract}
ABSTRAK
Keberhasilan pelaksanaan pembangunan dalam bidang kesehatan sangat tergantung pada peran aktif masyarakat karena masyarakat akan terlibat secara langsung dan lebih bertanggung jawab terhadap upaya penyelenggaraan pelayanan kesehatan berbasis masyarakat. Partisipasi masyarakat dalam pembangunan kesehatan yang mempunyai peran besar salah satunya adalah peran Kader Pos Pelayanan Terpadu (Posyandu).

Tujuan dari penelitian ini untuk mengetahui Hubungan Peran Kader terhadap Kunjungan Ibu Balita di Posyandu Kenanga Kampung Jawa Kelurahan Sekanak Raya Belakang Padang Kota Batam.

Penelitian ini adalah penelitian kuantitatif yang desain penelitiannya analitik yaitu penelitian yang di arahkan untuk menjelaskan suatu keadaan atau situasi dengan menggunakan pendekatan cross sectional. Metode yang digunakan dalam penelitian ini adalah angket.

Hasil penelitian ini menunjukkan adanya peran kader dari 39 orang yang aktif 32 orang $(82,1 \%)$, karakteristik berdasarkan umur terdapat 25 orang $(64,1 \%)$ berumur $36-40$ tahun, berdasarkan pendidikan terdapat 22 orang $(56,4 \%)$ SMP, berdasarkan pekerjaan terdapat 22 orang $(56,4)$ IRT, berdasarkan lama bekerja terdapat 34 orang $(87,2 \%)$. Kesimpulan dari penelitian ini menunjukkan tidak ada hubungan peran kader terhadap kunjungan ibu balita di Posyandu Kenanga Kampung Jawa Kelurahan Sekanak Raya Belakang Padang Kota Batam.
\end{abstract}

Kata Kunci : Peran Kader, Posyandu, Kunjungan Ibu Balita

\section{PENDAHULUAN}

Masalah kesehatan yang banyak terjadi di indonesia di antaranya adalah tingginya angka pertumbuhan penduduk, disparitas status kesehatan, beban ganda penyakit, yang mana data epidemiologi menunjukkan terjadi peningkatan prevalensi penyakit, baik penyakit menular yang baru dan lama maupun tidak menular, dan penyakit degeneratif, peningkatan kematian akibat kecelakaan dan menurunnya mutu kesehatan keluarga terutama kesehatan ibu dan anak.

Upaya percepatan penurunan angka kematian bayi dan angka kematian ibu, tentunya akan berhasil apabila melibatkan 
seluruh pemangku kepentingan baik unsur pemerintahan maupun unsur masyarakat dan dunia usaha. Kemudian untuk mengintegrasikan kegiatan seluruh kepentingan dalam rangka mempercepat penurunan angka kematian bayi dan angka kematian ibu, maka Posyandu menjadi salah satu lembaga yang paling tepat, karena keberadaannya sudah cukup lama dan terbukti berhasil mengatasi berbagai permasalahan yang berhubungan dengan kesehatan ibu dan anak, gizi, imunisasi, pemberantasan penyakit menular dan lain-lain, yang pada gilirannya akan berpengaruh terhadap rendahnya angka kematian ibu dan angka kematian bayi (Depkes RI, 2006).

Mengingat jumlah balita di indonesia sangat besar yaitu sekitar $10 \%$ dari seluruh populasi, maka sebagai calon generasi penerus bangsa, kualitas tumbuh kembang balita di indonesia perlu mendapat perhatian yang serius yaitu stimulasi yang memadai, ketersediaan pelayanan kesehatan dan asupan gizi yang baik.

Program posyandu dan peran serta kader dapat berjalan secara optimal dengan upayaupaya diantaranya pemahaman yang berasal dari pengetahuan yang baik, pelatihan/bimbingan dari puskesmas setempat dan pemberian penghargaan untuk meningkatkan motivasi. Seorang kader yang memiliki motivasi yang tinggi dan kemampuan yang bagus dalam menjalankan tugasnya akan menghasilkan kinerja yang baik. Motivasi kader dalam pelaksanaan posyandu merupakan suatu faktor dominan yang sangat berpengaruh terhadap tingkat pemanfaatan penimbangan balita.

Tugas kegiatan kader akan ditentukan, mengingat bahwa pada umumnya kader bukanlah tenaga profesional melainkan hanya membantu dalam pelayanan kesehatan. Dalam hal ini perlu adanya pembatasan tugas yang diemban, baik menyangkut jumlah maupun jenis pelayanan.

Berdasarkan studi pendahuluan yang dilakukan diketahui faktor yang mempengaruhi ibu balita tersebut tidak mematuhi jadwal kunjungan ke posyandu dikarenakan kesibukan dalam pekerjaan dan kurangnya informasi kepastian jadwal penyelengaraan posyandu didaerah tersebut serta cuaca yang kadang tidak menentu saat akan berkunjung ke posyandu.

Menurut data cakupan upaya kesehatan masyarakat dari Departemen Kesehatan RI 2013 bahwasanya cakupan kunjungan dan penimbangan balita di posyandu harus mencapai $71,4 \%$ dari total balita sebanyak 19.104.139 balita (Kemenkes, 2013). Karena dari data penimbangan tersebut bisa diketahui tingkat tumbuh kembang balita itu baik atau tidak. Sedangkan pencapaiannya di tahun 2012 baru sekitar 36,4\% dari total 15.505.184 balita indonesia (Depkes, 2012). Angka yang sangat jauh dari harapan menuju indonesia dengan generasi yang sehat dalam program MDG's 2016.

Berdasarkan data dari

Dinas Kesehatan Provinsi Kepulauan Riau menunjukkan 
pencapaian baru sekitar $54,9 \%$ yang melakukan kunjungan posyandu namun masih jauh dari target nasional yakni $71,4 \%$ (Dinkes Kepri, 2013). Data tersebut diperkuat pula dengan data kunjungan posyandu dari Dinas kesehatan Kota Batam yang menunjukkan sebanyak $54,2 \%$ dari total 80.864 balita di kota batam yang melakukan kunjungan posyandu. Angka ini masih berada di bawah target nasional (90\%). Angka ini masih jauh dari harapan target pencapaian Negara (Dinkes Batam, 2012).

Adapun data kunjungan posyandu balita yang rendah di beberapa puskesmas di wilayah kota Batam yakni Puskesmas Belakang Padang yang hanya mencapai $35,1 \%$ kunjungan balita di daerahnya, Puskesmas Sambau yang hanya $35,7 \%$ dan peringkat ketiga kunjungan posyandu balita terendah terdapat di Puskesmas Sei Pancur sebanyak 40,5\% (Dinkes Batam, 2012).

Pernyataan ini diperkua oleh penelitian yang dilakukan Mahasiswi Akademi Kebidanan Estu Utomo Boyoalali membuat skripsi tahun 2012 yang berjudul Peran Serta Kader dengan pelaksanaan posyandu balita di desa Tawengan dengan hasil secara signifikan peran serta kader dengan pelaksanaan posyandu balita. Diperoleh nilai sebesar $\quad 0,611 \quad(0,611>2,58)$ dengan $p$.value sebesar 0,0001 $(0,0001<0,05)$. Ada hubungan peran serta kader dengan pelaksanaan posyandu balita.

Berdasarkan studi pendahuluan di Kabupaten Takalar Propinsi Sulawesi Selatan yang memiliki berbagai program kesehatan tercatat memiliki 300 posyandu (Depkes RI, 2007), Sedangkan di wilayah kerja Puskesmas Towata Kecamatan Polombangkeng Utara Kabupaten Takalar yang terdiri dari 6 desa, terdapat 27 posyandu. Pada tahun 2008 rata-rata kader yang aktif sebesar 70 orang $(76,08 \%)$ yang tidak aktif 22 orang $(23,91 \%)$ dengan jumlah kader sebanyak 92 orang. Sedangkan tahun 2009 jumlah kader menurun menjadi 91 orang dengan rata-rata keaktifan sebesar 70 orang (76,92\%), yang tidak aktif 21 orang $(21,90 \%)$ dan untuk tahun 2010 jumlah kader meningkat menjadi 100 orang dengan ratarata keaktifan sebesar 71 orang $(79,20 \%)$, yang tidak aktif sebesar 21 orang $(20,58 \%)$.dan pada tahun 2011 jumlah kader sebanyak 68 orang dengan rata rata keaktifan sebesar 42 orang dan yang tidak aktif sebesar 26 Orang (Profil Puskesmas towata, 2010).

Dari data tersebut menunjukkan bahwa masih ada kader yang tidak aktif dalam setiap kegiatan posyandu yang dapat menimbulkan ketidakefektifan pelayanan Posyandu.

Maka disini upaya Puskesmas Belakang padang untuk mengakitfkan peran serta kader dalam kunjungan ibu balita di posyandu adalah dengan mengadakan penyuluhanpenyuluhan, memberikan pendidikan tentang kesehatan anak, agar kader dapat lebih aktif dan semangat dalam melakukan kegiatan di posyandu. 
Studi pendahuluan telah dilakukanguna memperjelas keterangan dari data Dinas Kesehatan Kota Batam tersebut. Diperoleh hasil bahwa di Puskesmas Belakang Padang terdapat 16 posyandu dan dengan jumlah kader 86 orang yang tersebar di sekitar wilayah puskesmas dan dari keseluruhan posyandu tersebut posyandu Kenanga yang terletak di Kampung Jawa menunjukkan masih banyak balita yang tidak melakukan kunjungan ke posyandu. Dari total 89 balita selama bulan januarisampai dengan bulan april 2016, tiap bulannya hanya sekitar 30-50 balita saja yang rutin melakukan kunjungan ke posyandu. Belum mencapai $50 \%$ kunjungan balita (Data Puskesmas Belakang Padang, 2016).

\section{METODE}

Jenis penelitian ini merupakan penelitian Penelitian Kualitatif. dengan metode pengumpulan data Cross sectional

Populasi adalah himpunan yang lengkap dari satuan-satuan atau indivudu-individu yang karakteristiknya ingin kita ketahui (Anggoro, 2008). Populasi pada penelitian ini yaitu seluruh kader di kelurahan sekanak raya belakang padang yang berjumlah 39 orang.

Metode pengambilan sampel dilakukan dengan cara Non Probability yaitu pengambilan sempel yang tidak didasarkan atas kemungkinan yang dapat diperhitungkan, tetapi semata-mata hanya berdasarkan kepada kepraktisan belaka (Notoatmojo, 2010).

Instrumen penelitian adalah alat yang akan digunakan untuk pengumpulan data (Notoatmodjo, 2010). Instrumen yang digunakan adalah kuisioner dan KMS untuk mengetahui karakteristik kader yakni usia, pekerjaan, pendidikan, lama menjadi kader untuk mendapatkan data peran kader terhadap kunjungan ibu balita di posyandu.

Uji analisis untuk mengukur hubungan antara variabel dependent dengan variabel independent dalam hal ini adalah peran kader terhadap kunjungan ibu balita di posyandu dengan menggunakan uji statistic $\mathrm{x}^{2}$ (Chi square goodness of fit).

\section{HASIL}

Analisa Univariat

\subsubsection{Hasil \\ Univariat}

Analisa

1. Variabel peran kader dapat dikelompokan menjadi 2 kelompok yaitu aktif dan tidak aktif. Dapat dilihat dari table berikut :

Tabel 5.2.1

Distribusi Frekuensi Peran Kader di Posyandu Kelurahan Sekanak Raya Belakang Padang Kota Batam

\begin{tabular}{|l|c|c|}
\hline $\begin{array}{l}\text { Pengetahu } \\
\text { an }\end{array}$ & $\begin{array}{l}\text { Frekuen } \\
\text { si }\end{array}$ & $\begin{array}{l}\text { Persenta } \\
\text { se }(\%)\end{array}$ \\
\hline Aktif & 32 & 82.1 \\
\hline Tidak aktif & 7 & 17.9 \\
\hline Total & 39 & 100 \\
\hline
\end{tabular}

Dari table 5.1 diatas menunjukan bahwa dari 39 kader di kelurahan sekanak raya puskesmas belakang 
padang, dapat diketahui bahwa yang aktif 32 orang kader $(82,1 \%)$ dibandingkan yang tidak aktif 7 orang kader $(17,9)$.

Distribusi frekuensi Karakteristik Kader Berdasarkan Umur

2. Distribusi

Frekuensi

Karakteristik Kader

Berdasarkan Umur Di

Posyandu Kenanga Kampung Jawa Kelurahan Sekanak Raya Belakang Padang Kota Batam 2016

\begin{tabular}{|c|c|c|}
\hline $\begin{array}{c}\text { Usia } \\
\text { Kader }\end{array}$ & $\begin{array}{c}\text { Frekuensi } \\
\text { (f) }\end{array}$ & $\begin{array}{c}\text { Persentasi } \\
(\%)\end{array}$ \\
\hline $\begin{array}{c}30-35 \\
\text { tahun }\end{array}$ & 13 & 33,3 \\
\hline $\begin{array}{c}36-40 \\
\text { tahun }\end{array}$ & 25 & 64,1 \\
\hline $\begin{array}{c}40-45 \\
\text { tahun }\end{array}$ & 1 & 2,6 \\
\hline JUMLAH & 39 & $100 \%$ \\
\hline
\end{tabular}

Dari tabel 5.2.1 diatas menunjukkan bahwa dari 39 Kader di Posyandu Kenanga Kampung Jawa Kelurahan Sekanak Raya Belakang Padang Kota Batam berdasarkan umur yaitu 13 orang $(33,3 \%)$ berumur 30-35 tahun, 25 orang $(64,1 \%)$ berumur 36-40 tahun, 1 orang $(2,6 \%)$ berumur $40-45$ tahun.

3. Distribusi

Karakteristik

Frekuensi berdasarkan Pendidikan Tabel 5.2.3

Distribusi

Karakteristik Frekuensi

Berdasarkan Pendidikan Di

Posyandu Kenanga

Kampung Jawa Kelurahan Sekanak Raya Belakang Padang Kota Batam 2016

\begin{tabular}{|c|c|c|}
\hline $\begin{array}{c}\text { Pendidikan } \\
\text { Kader }\end{array}$ & $\begin{array}{c}\text { Frekuensi } \\
\text { (f) }\end{array}$ & $\begin{array}{c}\text { Persentasi } \\
(\%)\end{array}$ \\
\hline SD & 1 & 2,6 \\
\hline SMP & 22 & 56,4 \\
\hline SMA & 16 & 41,0 \\
\hline JUMLAH & 39 & $100 \%$ \\
\hline
\end{tabular}

Dari tabel 5.2.3 diatas menunjukkan bahwa dari 39 Kader di Posyandu Kenanga Kampung Jawa Kelurahan Sekanak Raya Belakang Padang Kota Batam berdasarkan pendidikan yaitu 1 orang $(2,6 \%)$ berpendidikan $\mathrm{SD}, \quad 22$ orang $(56,4 \%)$ berpendidikan SMP dan 16 orang $(41,0 \%)$ berpendidikan SMA,

\section{Analisa Bivariat}

Hasil analisa bivariat bertujuan untuk mengetahui hubungan peran kader terhadap kunjungan ibu balita di posyandu kenanga kampung jawa kelurahan sekanak raya belakang padang kota batam 2016

Tabel 5.2.6

Distribusi frekuensi hubungan peran kader terhadap kunjungan ibu balita di Posyandu Kenanga Belakang Padang Kota Batam 2016 


\begin{abstract}
Dari tabel 5.2.6 diatas menunjukkan bahwa hasil penelitian peran kader terhadap kunjungan ibu balita di posyandu sebanyak 39 responden, kader yang aktif 32 orang (66.7\%) dan yang tidak aktif 7 orang $(33,3 \%)$ sedangkan kunjungan ibu balita dari 35 orang, yang patuh 19 orang $(59,4 \%)$ dan yang kurang patuh 13 orang $(40,6 \%)$.

Dari hasil perhitungan $\mathrm{Chi}$ Square didapatkan nilai $\mathrm{P}$ value sebesar 0,045 karena hasil $P$ value $>0,05$ berarti $\mathrm{H}_{\mathrm{a}}$ diterima $\mathrm{Ho}$ ditolak, maka dapat disimpulkan bahwa ada hubungan yang signifikan antara peran kader terhadap kunjungan ibu balita di posyandu.
\end{abstract}

\section{PEMBAHASAN}

\section{Pembahasan Univariat}

a. Peran Kader

Berdasarkan hasil penelitian, menunjukan bahwa dari 39 kader yang berperan dalam posyandu di kelurahan sekanak raya belakang padang dapat diketahui bahwa yang aktrif 32 orang $(82,1 \%)$ dan yang tidak aktif 7 orang ( 17,9\%) (Wikipedia, 2013).

b. Karakteristik kader

1. Dari karakteristik kader berdasarkan umur menunjukkan bahwa dari 39 kader didapatkan 13 orang $(33,3 \%)$ berumur 30-35 tahun, 25 orang $(64,1 \%)$ berumur $36-40$ tahun, 1 orang $(2,6 \%)$ berumur 40-45 tahun.

2. Dari karakteristik kader berdasarkan pendidikan menunjukkan bahwa dari 39 kader didapatkan 1 orang

$(2,6 \%)$ berpendidikan SD, 22

orang $\quad(56,4 \%)$

berpendidikan SMP dan

16 orang $(41,0 \%)$

berpendidikan SMA.

3. Dari karakteristik kader berdasarkan pekerjaan menunjukkan bahwa dari 39 kader didapatkan 22 orang $(56,4 \%)$ ibu rumah tangga, 4 orang $(10,3 \%)$ wiraswata dan 13 orang $(33,3 \%)$ swasta.

4. Dari karakteristik kader berdasarkan pendidikan menunjukkan bahwa dari 39 kader didapatkan 5 orang $(12,8 \%)<3$ tahun lama bekerja, dan 34 orang $(87,2 \%)>3$ tahun lama bekerja

c. Kunjungan ibu balita

Berdasarkan kunjungan ibu balita menunjukkan bahwa dari 35 ibu balita yang terdaftar di Posyandu Kenanga Belakang Padang, dapat diketahui bahwa lebih banyak ibu balita yang patuh dengan kunjungan ke posyandu sebanyak 24 orang $(68,6 \%)$ dibandingkan dengan yang kurang patuh terhadap kunjungan sebanyak 11 orang $(31,4 \%)$.

\section{Pembahasan Bivariat}

a. Hubungan peran kader terhadap kunjungan ibu balita di posyandu

Berdasarkan hasil penelitian Chi-Square didapatkan nilai $\mathrm{P}$ value sebesar 0,72 karena hasil $\mathrm{p}$ value $<0,05$ berarti $\mathrm{H}_{\mathrm{a}}$ diterima Ho ditolak, maka dapat disimpulkan bahwa ada hubungan yang 
signifikan antara peran kader terhadap kunjungan ibu balita di posyandu. Diketahui peran kader adalah salah satu factor yang mempengaruhi kunjungan ibu balita di posyandu dan peran kader juga sangat berpengaruh terhadap jalan nya pelaksaan kegiatan di posyandu (Jurnal Kebidanan, 2012).

\section{KESIMPULAN}

Berdasarkan hasil penelitian dan pengolahan data yang telah dilaksanakan oleh peneliti mengenai hubungan peran kader terhadap kunjungan ibu balita di posyandu kenanga kampong jawa kelurahan sekanak raya belakang padang kota batam 2016 dengan 39 responden, dapat disimpulkan bahwa:

a. Peran Kader terhadap kunjungan ibu balita di posyandu menunjukan bahwa dari 39 kader di kelurahan sekanak raya puskesmas belakang padang, dapat diketahui bahwa yang aktif 32 orang kader $(82,1 \%)$ dibandingkan yang tidak aktif 7 orang kader $(17,9)$.

b. Dari karakteristik kader berdasarkan umur menunjukkan bahwa dari 39 kader didapatkan 13 orang (33,3\%) berumur 30-35 tahun, 25 orang $(64,1 \%)$ berumur 36 40 tahun, 1 orang $(2,6 \%)$ berumur 40-45 tahun.

c. Dari karakteristik kader berdasarkan pendidikan menunjukkan bahwa dari 39 kader didapatkan 1 orang $(2,6 \%)$ berpendidikan SD, 22 orang $(56,4 \%)$ berpendidikan SMP dan 16 orang $(41,0 \%)$ berpendidikan SMA.

d. Dari karakteristik kader berdasarkan pekerjaan menunjukkan bahwa dari 39 kader didapatkan 22 orang $(56,4 \%)$ ibu rumah tangga, 4 orang $(10,3 \%)$ wiraswata dan 13 orang $(33,3 \%)$ swasta

e. Dari karakteristik kader berdasarkan pendidikan menunjukkan bahwa dari 39 kader didapatkan 5 orang $(12,8 \%)<3$ tahun lama bekerja, dan 34 orang $(87,2 \%)$ $>3$ tahun lama bekerja

f. Dari Kunjungan ibu balita menunjukkan bahwa dari 35 ibu balita yang terdaftar di Posyandu Kenanga Belakang Padang, dapat diketahui bahwa lebih banyak ibu balita yang patuh dengan kunjungan ke posyandu sebanyak 24 orang $(68,6 \%)$ dibandingkan dengan yang kurang patuh terhadap kunjungan sebanyak 11 orang $(31,4 \%)$.

g. Terdapat hubungan antara peran kader terhadap kunjungan ibu balita di Posyandu Kenanga Belakang Padang Kota Batam karena hasil perhitungan Chi-Square didapatkan nilai $\mathrm{P}$ value sebesar 0,039 karena hasil $\mathrm{P}$ value $<0,05$ berarti $\mathrm{H}_{\mathrm{a}}$ diterima Ho ditolak, maka dapat disimpulkan bahwa ada hubungan yang signifikan antara peran kader terhadap kunjungan ibu balita di posyandu. 
SARAN

1. Bagi Responden

Penelitian ini dapat menambah wawasan dan informasi kepada responden mengenai bagaimana peran kader dalam kegiatan posyandu dan terhadap kunjungan ibu balita di posyandu agar peran kader dapat berjalan dengan aktif dan dapat menjadi dasar bagi peneliti untuk penelitian selanjutnya.

2. Bagi Puskesmas

Penelitian ini dapat menjadi informasi dan sebagai masukan bagi petugas kesehatan di Puskesmas dan diharapkan dapat meningkatkan pelayanan kesehatan dalam memberikan penyuluhan, pendidikan terhadap kader-kader agar lebih aktif dan berperan di posyandu.

3. Bagi Institusi Pendidikan

Penelitian ini dapat sebagai masukan dan bermanfaat bagi mahasiswa STIKes Awal Bros Batam sebagai bahan perbandingan di masa yang akan datang yang berhubungan dengan penelitian ini dan bisa memberikan pengolahan data penelitian dengan analisa lain agar lebih disempurnakan

4. Bagi Masyarakat

Penelitian ini dapat memeberikan informasi tentang pentingnya peran kader dalam posyandu dan guna meningkatkan

pengetahuan dan

kepedulian masyarakat akan kepatuhan terhadap kunjungan ke posyandu.

5. Bagi Peneliti

Penelitian ini dapat menambah wawasan dan informasi kepada peneliti mengenai bagaimana hubungan antara peran kader terhadap kunjungan ibu balita, tumbuh kembang balita dan prean kader dalam kegiatan posyandu dapat menjadi dasar bagi peneliti untuk penelitian selanjutnya.

\section{DAFTAR PUSTAKA}

Eka, Arsita. 2012. Kesehatan ibu dan anak dalam millenium development goals (MDGs). Yogyakarta: Nuha Medika.

Hidayat, A.Aziz. 2011. Metode Penelitian Kebidanan dan Tekhnik Analisis Data. Jakarta: Salemba Medika.

KEPMENKES RI, 2010. Peraturan Menteri Kesehatan Republik Indonesia tentang Penggunaan Kartu Menuju Sehat (KMS) Bagi Balita.

KEMENKES RI, 2011. Pedoman Umum Pengelolaan Posyandu.

MENKES RI, 2012. Cakupan Penimbangan Balita 2011.

Marimbi, Hanum. 2010. Tumbuh kembang, status gizi balita, dan imunisasi dasar pada balita. Yogyakarta: Nuha Medika. 